\title{
Lifestyle Changes and Exacerbation Frequency of COPD in Times of the Pandemic
}

\author{
Fatma Tokgoz Akyil ${ }^{1}$, Seda Tural Onur ${ }^{1}$, Sinem Nedime Sokucu ${ }^{1}$, Hulya Abalı ${ }^{1}$, Neslihan \\ Boyraci $^{1}$, Elif Çayır ${ }^{1}$, and Sedat Altın ${ }^{1}$ \\ ${ }^{1}$ Yedikule Chest Diseases and Thoracic Surgery Training and Research Hospital
}

May 24, 2021

\begin{abstract}
Aim: The aim of this study is to analyze COPD exacerbation rates and the effect of patients' behavioral changes on the exacerbations during the pandemic. Materials and Methods: Conducted in a reference hospital for chest diseases, patients hospitalized with an exacerbation of COPD between 11.03.2019 and 11.03.2020 were designated. Patients' COPD exacerbations requiring emergency department (ED) visits and/or hospitalization were compared between 11.03.2019 - 25.12.2019 (pre-pandemic period) and 11.03.2020 - 25.12.2020 (pandemic period). Each patient was surveyed with 25 questions using telemedicine. Results: Of all the 256 patients, $203(79 \%)$ were male and the mean age was $66 \pm 10$. Compared to the previous year, ED visits and hospitalizations in our hospital were significantly lower and less frequent ( $\mathrm{p}<0.0001$, for both). Smoking habit decreased in $9 \%$, and $60 \%$ had hardly spent time in outdoors (e.g., parks and gardens). Only three patients reported to spend time indoors (e.g., cafes and restaurants). Household mask-use rate while contacting the patient was $50 \%$. As a COPD patient, $33 \%$ expressed themselves as "feeling better". Overall, $92(36 \%)$ patients were recorded not to have any exacerbation, 34 (13\%) to have no attacks of worsening that they were managed at home. Novel exacerbation risk was found to independently correlate with younger age (OR: 0.944,CI:0.904-0.986, $\mathrm{p}=0.010$ ) and having more frequent episodes of exacerbation in the pre-pandemic period (OR:1.2,CI:1.025-1.405, $\mathrm{p}=0.023$ ). Conclusion: COPD patients specifically benefited from confinements, restrictions and lifestyle changes. Further studies are needed to better identify the most critical factors leading to these positive outcomes. A permanent patient management guideline for COPD patients could be formulated where the weight of lifestyle factors is elevated.
\end{abstract}

\section{Hosted file}

copd_pandemic_full_text_22.5.21.doc available at https://authorea.com/users/415359/articles/ 523268-lifestyle-changes-and-exacerbation-frequency-of-copd-in-times-of-the-pandemic 

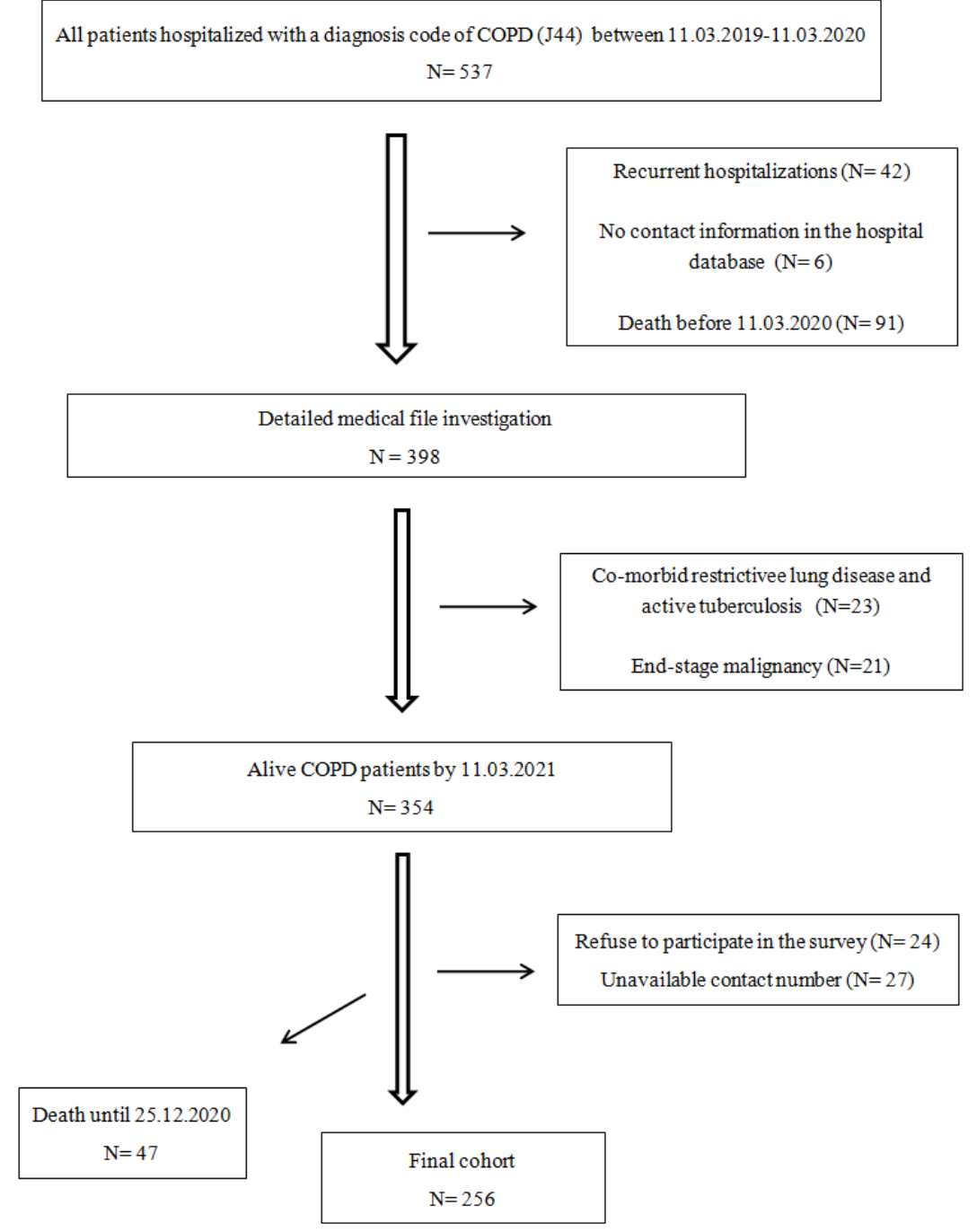